\title{
Monitoring metabolic parameters of the ischaemic brain
}

\author{
Girija P. Rath
}

\section{INTRODUCTION}

The metabolic parameters of ischaemic brain are continuously monitored by 'cerebral microdialysis' (MD) which is a minimally invasive technique and one of the most recent additions to the neuromonitoring armamentarium. After Ungerstedt and Pycock improvised the design of MD probe and made it suitable for human use, MD was introduced to the clinical practice in the mid-1990s. ${ }^{[1,2]}$ It works on the 'principle of dialysis' where there is diffusion of water-soluble molecules from higher concentration to an area of lower concentration through a semipermeable membrane. The MD catheter consists of a fine double lumen probe, lined at its tip with the semi-permeable dialysis membrane. The catheter tip is placed into brain parenchyma and perfused via an inlet tube with fluid isotonic to the tissue interstitium known as 'artificial CSF' or perfusate. The perfusate passes along the membrane before exiting via outlet tubing into a special collecting chamber called 'microvial' ${ }^{[3]}$ Diffusion drives the passage of molecules across the membrane along their concentration gradient. The MD catheter, therefore, acts an 'artificial blood capillary', and the concentration of substrate in the collected fluid (microdialysate) will depend in part on the balance between substrate delivery to and uptake from the extracellular fluid (ECF). Hence, any molecule small enough to pass through the membrane can be sampled in the microvial after a predefined period (usually $1 \mathrm{~h}$ ). These microvials are then placed on the bedside MD monitor for brain tissue biochemical analysis.

Department of Neuroanaesthesiology and Critical Care, Neurosciences Centre, All India Institute of Medical Sciences, New Delhi, India

\begin{tabular}{|l|l|}
\hline \multicolumn{2}{|c|}{ Access this article online } \\
\hline Quick Response Code: & Website: \\
\hline & www.jnaccjournal.org \\
\cline { 2 - 3 } & \\
\hline
\end{tabular}

\section{RELATIVE RECOVERY}

The proportion of the true ECF concentration collected in the dialysate is termed the relative recovery. It is dependent on the pore size and area of the semi-permeable membrane and the rate of flow of perfusate through the membrane. ${ }^{[3,4]}$ The membrane usually measures $10 \mathrm{~mm}$ in length and permits substances with molecular weight $<20 \mathrm{kDa}$. Newer MD catheters (CMA 71) help collection of larger molecules with molecular weight up to $100 \mathrm{kDa}$. The infusion rate of perfusate varies from 0.3 to $3.0 \mu \mathrm{l} / \mathrm{min}$. Although at a low flow rate of $0.1 \mu \mathrm{l} / \mathrm{min}, 100 \%$ recovery dialysate is possible, the flow rate is normally kept at a fixed rate of $0.3 \mu \mathrm{l} / \mathrm{min}$ to allow collection of adequate sample volume of the substance to be analysed (analyte) within the stipulated period. During intraoperative MD to achieve a quick recovery of microdialysate and short event detection time, a faster flow rate $(1 \mu \mathrm{l} / \mathrm{min})$ is utilised. Similarly, the recovery rate can be increased by using higher surface area of the semipermeable membrane; a membrane length $30 \mathrm{~mm}$ provides $100 \%$ recovery. Nevertheless, the concentration in the dialysate depends not only on the rate of flow and length of the membrane but also on the supply of different substances from the blood capillaries and the uptake and release from the cells.

\section{MARKERS OF BRAIN ISCHAEMIA AND CELL DAMAGE}

Under normal circumstances, glycolysis takes place in the cytoplasm, wherein glucose is converted to pyruvate producing two molecules of adenosine triphosphate (ATP). ${ }^{[3]}$ Under aerobic conditions,

This is an open access article distributed under the terms of the Creative Commons Attribution-NonCommercial-ShareAlike 3.0 License, which allows others to remix, tweak, and build upon the work non-commercially, as long as the author is credited and the new creations are licensed under the identical terms.

For reprints contact: reprints@medknow.com

How to cite this article: Rath GP. Monitoring metabolic parameters of the ischaemic brain. J Neuroanaesthesiol Crit Care 2016;3:56-8. 
pyruvate dehydrogenase converts pyruvate into acetyl coenzyme A which in turn enters into mitochondrial citric acid cycle where oxygen is utilised to produce 36 molecules of ATP. In the absence of oxygen, lactate dehydrogenase converts pyruvate to lactate. Increase in lactate and decrease in pyruvate indicate decreased oxygen availability, which may be due to ischaemia or hypoxia. A normal lactate value in dialysate is about $2 \mathrm{mM}$ and pyruvate about $120 \mathrm{uM} .^{[5]}$ The normal lactate-pyruvate ratio (LPR) is approximately 20 and a value more than 25 signifies onset of metabolic crisis. An increased LPR may be seen in the conditions with ischaemic changes and mitochondrial dysfunction. LPR is the more reliable MD marker than lactate or pyruvate as it is independent of catheter recovery, and hence, it is most widely measured MD variable.

In the absence of oxygen and ATP, the failure of ionic pumps leads to calcium influx into cells and activation of various enzymes; it results in disruption of cell membrane function and degradation of the membrane. Glycerol is one of the constituents of triglycerides forming the cell membranes. An increase in the level of glycerol from 50 to $100 \mathrm{uM}$ indicates cell damage. ${ }^{[4,5]}$ A 4-8-fold increase in glycerol concentration has been recorded in sever-to-complete ischaemia.

Glutamate is a marker of excitotoxicity. It opens calcium channels, increases intracellular concentration of calcium resulting in cell damage. ${ }^{[5]}$ Normal glutamate level is $10 \mathrm{uM}$. Cerebral ischaemia is associated with increased MD glutamate concentration.

The microdialysate glucose levels may be affected by ischaemia, hyperaemia, hyperglycaemia, hypermetabolism or hypometabolism. If brain glucose increases or decreases disproportionally to blood sugar levels, then the changes in blood flow or metabolism are the reasons behind it. The normal microdialysate value of glucose is taken as $2 \mathrm{mM}$ using a $10 \mathrm{~mm}$ dialysis membrane and $0.3 \mathrm{ul} / \mathrm{min}$ of perfusate flow rate.

\section{PLACEMENT OF THE MICRODIALYSIS CATHETER}

MD catheter is placed in the brain parenchyma either during an open craniotomy procedure or percutaneously, through a burr hole using cranial access device. Multi-lumen cranial access device helps simultaneous placement of different monitoring sensors such as intracranial pressure (ICP), brain tissue oxygen tension and temperature. The tip of the MD catheter contains radio-opaque gold to confirm placement of catheter using computed tomographic scan where it looks like a dot contusion. In patients with traumatic brain injury (TBI), the catheter is generally not placed in contused or infarcted tissue and placed in the penumbra as analysis of the MD marker help to determine the metabolic state of the 'at-risk area'. Hence, the catheter tip should be placed in the 'at-risk' pericontusional tissue 'penumbra' ${ }^{[5,6]}$ In case of adversity, appropriate manipulation of the physiologic variable such as cerebral perfusion pressure (CPP), brain oxygenation and glucose supply would salvage these areas. A second catheter may be placed in normal brain to compare with the normal values. However, in diffuse axonal injury, it should be placed right frontal lobe as it is the non-dominant hemisphere. In cases of subarachnoid haemorrhage (SAH), the catheter is placed in the vascular territory of the parent vessel of the ruptured aneurysm that is affected by vasospasm. ${ }^{[7]}$ During catheter insertion, there may be minimal trauma to the adjacent which makes the analyte values (abnormally high) during $1^{\text {st }} h$ unreliable. ${ }^{[5]}$

\section{DATA INTERPRETATION}

To achieve optimum clinical benefit during patient management, the biochemical markers of MD is better to be monitored along with other physiological variables such as ICP, $\mathrm{CPP}$ and $\mathrm{PbtO}_{2}$. The MD markers are usually interpreted by '(Level, Trend and Comparison) LTC method' ${ }^{[3,5,8]}$ As per this method, the level of biomarkers is confirmed whether within physiological range or not. The trend of the variables in recent hours is considered important rather than the absolute values. Moreover, a comparison is simultaneously made with other neurophysiologic variables (e.g. ICP, $\mathrm{CPP}$ and $\mathrm{PbtO}_{2}$ ).

The presence of low glucose, increased glycerol and glutamate and increased LPR on MD indicates the presence of ischaemic/hypoxic episodes in the brain. ${ }^{[5]}$ Increased glycerol may suggest cell membrane degradation whereas the increased glutamate is also suggestive of excitotoxicity.

\section{APPLICATIONS OF MICRODIALYSIS IN DIFFERENT CLINICAL SCENARIO}

Several uses of MD have been described in the literature which is beyond scope of this article; few practical applications are described here for the benefit of the readers.

\section{Traumatic brain injury}

In patients with TBI, MD predicts intracranial hypertension few hours before its occurrence; the glycerol and LPR values are raised. ${ }^{[5,8]}$ Hence, the ischaemic changes can be detected much before the changes of neurological status of the patient or with the other physiological monitoring variables such as ICP. Therefore, the MD markers can be utilised to individualise CPP management, evaluate tissue perfusion and oxygenation and assess physiologic 
response to therapy such as hyperventilation, sedation and various surgical interventions. Few reports suggest that MD helps prognostication in patients with TBI. ${ }^{[9]} \mathrm{A}$ persistently low glucose value is associated with poor outcome 6 months after the injury. MD also predicts anatomical alterations, a persistently elevated LPR in patients with normal frontal lobe, but severe head injury may develop frontal lobe atrophy at 6-month period. ${ }^{[10]}$

\section{Subarachnoid haemorrhage}

The patients with SAH often develop cerebral vasospasm which leads to cerebral ischaemia. It has been observed that the MD detects possibility of ischaemic changes much before the development of clinical symptoms of 'delayed ischaemic neurologic deficit' following cerebral vasospasm. There is a significant elevation in lactate, LPR and glutamate among the symptomatic cases. ${ }^{[11-13]}$ Hence, it indirectly helps guiding triple-H therapy, especially in the unconscious patients.

\section{Ischaemic stroke}

Severe hemispheric stroke is associated with high mortality because of development of fatal brain oedema. MD can be used to monitor hemispheric stroke (ischaemic penumbra or malignant brain oedema in major vessel occlusion). The neurochemical alterations contralateral to side of infarction may proceed few hours before clinical signs of herniation. ${ }^{[14,15]}$ In addition, following decompressive craniectomy, the biochemical abnormalities return to normal as the ICP is decreased. Hence, MD may be utilised for as a potential guide for surgical intervention following malignant middle cerebral artery infarction.

\section{CONCLUSION}

MD is a promising technology for the continuous monitoring of metabolic parameters of ischaemic brain. It is yet to be introduced into routine clinical practice and is still considered as a research tool with its restricted availability in few apex centres. As it possesses a unique ability to provide information on secondary brain injury, in future, MD may become a key component of multimodal monitoring in neurointensive care units.

\section{Financial support and sponsorship}

Nil.

\section{Conflicts of interest}

There are no conflicts of interest.

\section{REFERENCES}

1. Ungerstedt $U$, Pycock C. Functional correlates of dopamine neurotransmission. Bull Schweiz Akad Med Wiss 1974;30:44-55.

2. Meyerson BA, Linderoth B, Karlsson H, Ungerstedt $U$. Microdialysis in the human brain: Extracellular measurements in the thalamus of parkinsonian patients. Life Sci 1990;46:301-8.

3. Ghosh A, Smith M. Brain tissue biochemistry. In: Matta BF, Menon DK, Smith M, editors. Core Topics in Neuroanesthesia and Neurointensive Care. Cambridge University Press; 2011. p. 85-100.

4. Ungerstedt $U$, Rostami E. Microdialysis in neurointensive care. Curr Pharm Des 2004;10:2145-52.

5. Tisdall MM, Smith M. Cerebral microdialysis: Research technique or clinical tool. Br J Anaesth 2006;97:18-25.

6. Engström M, Polito A, Reinstrup P, Romner B, Ryding E, Ungerstedt $U$, et al. Intracerebral microdialysis in severe brain trauma: The importance of catheter location. J Neurosurg 2005;102:460-9.

7. Bellander BM, Cantais E, Enblad P, Hutchinson P, Nordström $\mathrm{CH}$, Robertson $\mathrm{C}$, et al. Consensus meeting on microdialysis in neurointensive care. Intensive Care Med 2004;30:2166-9.

8. Timofeev I, Hutchinson P. Microdialysis. In: Gupta AK, Gelb AW, editors. Essentials of Neuroanesthesia and Neurointensive Care. Philadelphia: Saunders, Elsevier; 2008. p. 277-82.

9. Oddo M, Schmidt JM, Carrera E, Badjatia N, Connolly ES, Presciutti M, et al. Impact of tight glycemic control on cerebral glucose metabolism after severe brain injury: A microdialysis study. Crit Care Med 2008;36:3233-8.

10. Marcoux J, McArthur DA, Miller C, Glenn TC, Villablanca P, Martin NA, et al. Persistent metabolic crisis as measured by elevated cerebral microdialysis lactate-pyruvate ratio predicts chronic frontal lobe brain atrophy after traumatic brain injury. Crit Care Med 2008;36:2871-7.

11. Bhatia R, Hashemi P, Razzaq A, Parkin MC, Hopwood SE, Boutelle MG, et al. Application of rapid-sampling, online microdialysis to the monitoring of brain metabolism during aneurysm surgery. Neurosurgery 2006;58 4 Suppl 2:ONS-313-20.

12. Unterberg AW, Sakowitz OW, Sarrafzadeh AS, Benndorf G, Lanksch WR. Role of bedside microdialysis in the diagnosis of cerebral vasospasm following aneurysmal subarachnoid hemorrhage. J Neurosurg 2001;94:740-9.

13. Helbok R, Schiefecker A, Delazer M, Beer R, Bodner T, Pfausler B, et al. Cerebral tau is elevated after aneurysmal subarachnoid haemorrhage and associated with brain metabolic distress and poor functional and cognitive long-term outcome. J Neurol Neurosurg Psychiatry 2015;86:79-86.

14. Berger C, Kiening K, Schwab S. Neurochemical monitoring of therapeutic effects in large human MCA infarction. Neurocrit Care 2008;9:352-6.

15. Nielsen TH, Schalén W, Ståhl N, Toft P, Reinstrup P, Nordström $\mathrm{CH}$. Application of bedside diagnosis of mitochondrial dysfunction after malignant middle cerebral artery infarction. Neurocrit Care 2014;21:35-42. 